\title{
PENGARUH KONSENTRASI EKSTRAK BAWANG MERAH (Allium cepa) TERHADAP PERTUMBUHAN STEK LADA (Piper nigrum L.)
}

\author{
Josina I.B. Hutubessy \\ irenehutubessy91@yahoo.co.id
}

\section{Program Studi Agroteknologi, Fakultas Pertanian, Universitas Flores}

\begin{abstract}
ABSTRAK
This research aims to know the effect of the concentration of shallot extract as well as the optimum concentration of shallots extract on the growth of pepperplant.

The method used in this study was Randomized Block Design with the treatment used is Eo (without concentration), El (the concentration of $100 \mathrm{ppm}$ ), E2 (concentration of $200 \mathrm{ppm}$ ), E3 (concentration of $300 \mathrm{ppm}$ ), E4 (concentration of $400 \mathrm{ppm}$ ). Observationvariablesin this study is height of plant $(\mathrm{cm})$, length of root $(\mathrm{cm})$, total number of roots, number of shoots, weight of fresh residuestan ${ }^{-1}$, dry oven weight of residues.

The results showed thatno interaction between shallotsextracts (Allium cepa L.) and the growth of pepper plant (Piper nigrum L.) which effect on the optimal growth of pepper plant.
\end{abstract}

Keywords:concentration, shallotsextract, pepper plant

\section{PENDAHULUAN}

Daerah penghasil terbesar tanaman lada adalah Lampung, Bangka dan Bengkulu. Sebanyak $\pm 98 \%$ perkebunan lada diusahakan oleh rakyat (Departemen Kehutanan dan Perkebunan, 2003). Petani di Kabupaten Ende lebih banyak membudidayakan lada menggunakan biji. Perbanyakan dengan cara generatif (biji) selalu menghadapi kendala seperti tumbuhnya kurang seragam, waktu mulai berproduksi lebih lama dan mass produktif lebih singkat (Wisnaya, 1990). Sementara itu perbanyakan secara vegetatif dapat dilakukan melalui okulasi, penyambungan dan stek, dari ketiga cara perbanyakan tanaman secara vegetatif cara yang paling banyak diusahakan adalah dengan cara stek.

Perbanyakan bahan tanaman dengan cara stek memiliki kelebihan seperti sifat tanaman yang dikehendaki dapat tedamin sesuai dengan induknyaa sebab cumber stek diambil langsung dari potion induk yang telah diketahui sifat fisik dan produksinya,waktu mulai produksi lebih cepat dan seragam Berta jangka waktu produksi lebih lama, sedangkan pengembangan tanaman lada dengan menggunakan sambungan seringmenemui kendala yaitu pads bagian sambungan 
Josina: Pengaruh konsentrasi ekstrak bawang merah (allium cepa) terhadap pertumbuhan stek lada (Piper nigrum L.)

Bering terjadi pembengkakan sehingga dapat menjadi sarang hams dan penyakit yang tentunya akan berpengaruh langsung terhadap keberhasilan pertumbuhan tanaman di pembibitan (Rismunandar, 1987).

Stek batang sebagai material sangat menguntungkan, sebab batang mempunyai persediaan makanan yang cukup terhadap tunas-tunas batang dan akar, dan juga dapat dihasilkan dalam jumlah besar (Rochimin dan Hadadi, 1973). Upaya pembiakan secara vegetatif dengan tujuan untuk memperoleh persentase tumbuh tanaman yang tinggi, adanya peningkatan sistem pertumbuhan perakaran, serta bibit tanaman yang ditanam lebih mampu dan cepat beradaptasi dengan lingkungan yang barn perlu dilibatkan pula penggunaan hormon tumbuh akar melalui berbagai uji coba untuk mendapatkan konsentrasi dan lama perendaman yang tepat dalam penggunaannya sehingga diperoleh basil yang lebih baik bagi pengaturan dan pertumbuhan tanaman (Rismunandar, 1987).

Perbanyakan tanaman lada menggunakan stek, diambil dengan satu runs atau lebih (Anonimus, 2002). Salah satu indikasi stek lada yang baik adalah tumbuhnya akar stek dengan baik, sehingga dapat menunjang pertumbuhan stek hingga pada akhirnya bibit siap dipindah ke lapangan. Banyak faktor yang berpengaruh terhadap pertumbuhan stek lads termasuk penggunaan media tanam dan zat pengatur tumbuh. Penggunaan zat pengatur tumbuh dimaksudkan untuk meningkatkan daya tumbuh bibit lada dengan merangsang pembentukan akar lebih cepat.Kegagalan pertumbuhan tanaman di pembibitanyakni $60 \%$ adalah akibat tidak digunakan zat pengatur tumbuh.

Uji ekstrak bawang merah sebagai zat pengatur tumbuh digunakan pada tanaman cabai besar merah yang mampu menaikkan ketahanan tanaman terhadap serangan hams dan meningkatkan daya adaptasi agar tetap normal di saat panen. Uji yang digunakan pada tanaman cabai besar merah mampu meningkatkan pertumbuhan akar, tunas, batang, daun dan bunga sehingga menghasilkan buah selama panen pertama 12 buah dan berat mencapai 350 gram, memiliki usia jauh lebih panjang selama 2,5 tahun atau setara 29 bulan, dan basil berat buah naik hingga 540 buah tiap panen.

Beberapa jenis hormon tumbuh yang sering digunakan antara lain Indole Actic Acid (IAA), Indole-3-Butiric Acid (IBA), 1Naphtalene-Acetamide (NAD), 2-Methyl-1Naphtaleneacetic Acid (MNAA), 3-Methyl1-Naphtalene-Acetamide (MNAD), dan Tetramethyl-Thiuram-Disulfide (Thiram). Ekstrak bawang merah digunakan sebagai 
Josina: Pengaruh konsentrasi ekstrak bawang merah (allium cepa) terhadap pertumbuhan stek lada (Piper nigrum L.)

pengganti Rootone-f untuk mempercepat dan memperbanyak keluarnya akar-akar baru, karena di dalam ekstrak bawang merah mengandung bahan aktif berupa hormon tumbuh akar yaitu Auksin (60\%) dan Giberelin (75\%) (Setyowati, 2004).

Auksin yang terkandung dalam ekstrak bawang merah memiliki kemampuan untuk menstimulasi pembentukan kalus, dimana kalus merupakan awal dari pembentukan akar pads stek pucuk jati. Hasil penelitian membuktikan bahwa pertumbuhan akar stek pucuk jati yang diberi ekstrak bawang merah relatif bagus meskipun panjang akarnya masih lebih pendek dari akar stek jati. Hal tersebut disebabkan karena bawang meran mengandung hormon auksin yang berfungsi menstimulasi pertumbuhan akar.

Upaya perbaikan teknik budidaya lada melalui proses pembiakan secara vegetatif dengan stek batang yang menggunakan ekstrak bawang merah sebagai zat perangsang tumbuh merupakan implementasi program pemerintah sehubungan dengan peningkatan keberhasilan pembibitan tanaman lada. Upaya ini dilakukan untuk menggali dan mengembangkan cumber-cumber hormon dari bahan alarm yang murah dan mudah didapatkan oleh petani. Salah satunya adalah dengan menggunakan ekstrak umbi bawang merah. Di Indonesia bawang merah adalah salah satu rempah multiguna yang dapat ditemukan kapan dan di mana saja. Berdasarkan uraian di atas, mendorong penulis untuk melakukan penelitian dengan judul"PengaruhKonsentrasi Ekstrak Bawang Merah (Allium cepa) Terhadap Pertumbuhan Stek Lada (Piper nigrum L.)". Dengan tujuan untuk mengetahui pengaruh konsentrasi ekstrak bawang merah terhadap pertumbuhan stek lada, serta konsentrasi optimum ekstrak bawang merah yang dapat memberikan pertumbuhan optimal pada stek lada.

\section{METODE PENELITIAN}

\section{Tempat dan Waktu}

Penelitian dilaksanakan di Desa Ndorurea I, Kecamatan Nangapanda, Kabupaten Ende. Penelitian dilaksanakan pada. bulan Februari sampai Mei 2013.

\section{Bahan dan Alat}

Bahan yang akan digunakan dalam penelitian ini adalahstek lada, bawang merah, air sedangkan alat yang digunakan adalah pilau, ember plastik, polibag, alat penyemprot, blender, kain flanel, gelas ukur, mistar, jangka sorong, alat tulis dan kalkulator.

\section{Rancangan Penelitian}

Rancangan penelitian yang digunakan 
Josina: Pengaruh konsentrasi ekstrak bawang merah (allium cepa) terhadap pertumbuhan stek lada (Piper nigrum L.)

adalah Rancangan Acak Kelompok (RAK) dengan pola faktor tunggal yang terdiri dari lima perlakuan yaitu:

EO : Konsentrasi 0 ppm.

El : Konsentrasi 100 ppm.

E2 : Konsentrasi 200 ppm.

E3 : Konsentrasi 300 ppm.

E4 : Konsentrasi 400 ppm.

Setiap perlakuan terdiri dari 7 pot dan diulang sebanyak 4 kali schingga terdapat 140 pot percobaan. Denah percobaan disajikan dalam Gambar 3.2.

\section{Pelaksanaan Penelitian}

\section{Penyiapan Sungkup}

Sungkup dibuat dari bambu dengan ukuran $3 \mathrm{~m} \times 2 \mathrm{rn} \times 3 \mathrm{~m}$ dengan dinding dibuat dari daun kelapa dan atapnya dari plastik transparan. Sungkup disiapkan I unit.

\section{Penyiapan Media Tanam}

Polibag yang disiapkan berukuran sedang, berdiameter $15 \mathrm{~cm}$ dan tinggi 30 cm, sebanyak 140 buah. Polibag diisi dengan media tanam yang merupakan campuran tanah kebun dan pupuk kandang dengan perbandingan $2: 1$.

\section{Penyiapan Stek Lada}

Stek lada diambil dari tanaman induk yang berumur dua tahun, berasal dari cabang ortotrop dan cabang gantung masing-masing sebanyak 140 stek. Cabang tersebut dipotong menjadi stek berukuran $20 \mathrm{~cm}$ atau 2 ruas.Stek dari pohon induk yang sehat berumur 2 (dua) tahun, sudah berkayu, daun hijau tea dan tidak ada gejala abnormal.

\section{Pembuatan Ekstrak Bawang Merah dan Aplikasi}

Infundasi adalah metode ekstraksi dengan pelarut air. Pada waktu proses infundasi berlangsung, temperatur pelarut air hares mencapai suhu $90^{\circ} \mathrm{C}$ selama 15 menit. Rasio berat bahan dan air adalah 1 : 10. Bahan ekstrak dipanaskan dalam panci dengan air secukupnya selama 15 menit terhitung mulai suhu mencapai $90^{\circ} \mathrm{C}$ sambil diaduk. Penyaringan dilakukan saat ekstrak masih panas melalui kain flanel, tambahkan air panas secukupnya melalui ampas hingga diperoleh volume yang diinginkan. Metode ekstraksi dengan infundasi adalah sebagai berikut: sebanyak 1000 gr bawang merah dan $500 \mathrm{ml}$ air diblender hingga halus lalu dipanaskan dalam panci di atas kompor sambil diaduk selama 15 menit pada suhu $90^{\circ} \mathrm{C}$ kemudian diangkat dan disaring pada spat ekstrak masih dalam kondisi panas dengan kain Hanel kemudian tambahkan air panas secukupnya untuk mendapatkan 600 ml ekstrak bawang merah. Penentuan konsentrasi ekstrak bawang merah dilakukan dengan cars: konsentrasi 0 ppm (tanpa ekstrak bawang merah), Konsentrasi 100 
Josina: Pengaruh konsentrasi ekstrak bawang merah (allium cepa) terhadap pertumbuhan stek lada (Piper nigrum L.)

ppm adalah campuran $100 \mathrm{ml}$ ekstrak bawang merah dengan $900 \mathrm{ml}$ air. Konsentrasi 200 ppm adalah campuran 200 $\mathrm{ml}$ ekstrak bawang merah dengan $800 \mathrm{ml}$ air. Konsentrasi 300 ppm adalah campuran $300 \mathrm{ml}$ ekstrak bawang merah dengan 700 $\mathrm{ml}$ air, dan konsentrasi 400 ppm adalah campuran $400 \mathrm{ml}$ ekstrak bawang merah dengan $600 \mathrm{ml}$ air.

\section{Penanaman dan Pemeliharaan Stek Lada}

Bahan yang diambil adalah stek tanaman lade pada bagian tengah dengan panjang 2 rues, kemudian stek direndam selama 15 menit dalam ekstrak bawang merah sesuai konsentrasi yang telah ditetapkan. Setelah selesai proses perendaman kemudian ditanam dalam polibag dengan kedalaman $2 \mathrm{~cm}$ dan setiap polibag ditanam 2 stek. Polibag diletakkan sesuai dengan denah percobaan. Stek disiram 2 kali sehari pada pagi dan sore.

\section{Variabel Pengamatan}

1. Tinggi tanaman $(\mathrm{cm})$ diukur dengan menghitung bagian batang tanaman yang baru muncul pada masa tumbuh. Waktu pengamatan pada umur $30,45,60,75$, 90 hst.

2. Panjang akar $(\mathrm{cm})$.

Pengamatan panjang akar diukur dengan mistar dari pangkal batang sampai ujung akar terpanjang. Waktu pengamatan pada umur 30, 45, 60, 75, 90 hst.

3. Jumlah akar.

Pengamatan jumlah akar dilakukan dengan cara mencabut tanaman (destruktif).Waktu pengamatan pada umur 30, 45, 60, 75, 90 hst.

4. Jumlah tunas.

Jumlah tunas dihitung dengan menghitung bagian tunas tanaman yang baru muncul. Waktu pengamatan pada umur 30, 45, 60, 75, 90 hst.

5. Berat segar berangkasan.

Berat segar berangkasan tan 1 diperotch dengan cara menimbang seturuh bagian tanaman. Pengamatan dilakukan pada umur 90 hst.

6. Berat kering oven berangkasan.

Berat kering oven berangkasan diperoleh dengan cara mengoven seluruh bagian tanaman sampai mencapai berat kering konstan. Pengamatan ini dilakukan pada umur 90 hst.

\section{Analisis Data}

Data dianalisis dengan menggunakan analisis sidik ragam. Apabila perlakuan menunjukkan pengaruh yang nyata terhadap variabel yang diamati, maka dilanjutkan dengan Uji BNT 5\% (Gomez dan Gomez, 1995).

\section{HASIL DAN PEMBAHASAN}

Hasil analisis statistika menunjukkan 
Josina: Pengaruh konsentrasi ekstrak bawang merah (allium cepa) terhadap pertumbuhan stek lada (Piper nigrum L.)

bahwa pengaruh konsentrasi ekstrak bawang

merah (Allium cepa $L$ ) tehadap pertumbuhan tidak nyata terhadap semua variabel pengamatan.

stek lada (Piper nigrum L.) berpengaruh

Tabel 4.1 Signifikasi Pengaruh pengaruh konsentrasi ekstrak bawang merah (Allium cepa L.) tehadap pertumbuhan stek lada (Piper nigrum L)

\begin{tabular}{clc}
\hline No. & \multicolumn{1}{c}{ Variabel } & Signifikasi \\
\hline 1 & Tinggi tanaman umur $30 \mathrm{hst}$ & $\mathrm{TN}$ \\
2 & Tinggi tanaman umur $45 \mathrm{hst}$ & $\mathrm{TN}$ \\
3 & Tinggi tanaman umur $60 \mathrm{hst}$ & $\mathrm{TN}$ \\
4 & Tinggi tanaman umur $75 \mathrm{hst}$ & $\mathrm{TN}$ \\
5 & Tinggi tanaman umur $90 \mathrm{hst}$ & $\mathrm{TN}$ \\
6 & Panjang akar umur $30 \mathrm{hst}$ & $\mathrm{TN}$ \\
7 & Panjang akar umur $45 \mathrm{hst}$ & $\mathrm{TN}$ \\
8 & Panjang akar umur $60 \mathrm{hst}$ & $\mathrm{TN}$ \\
9 & Panjang akar umur $75 \mathrm{hst}$ & $\mathrm{TN}$ \\
10 & Panjang akar umur $90 \mathrm{hst}$ & $\mathrm{TN}$ \\
11 & Jumlah akar umur $30 \mathrm{hst}$ & $\mathrm{TN}$ \\
12 & Jumlah akar umur $45 \mathrm{hst}$ & $\mathrm{TN}$ \\
13 & Jumlah akar umur $60 \mathrm{hst}$ & $\mathrm{TN}$ \\
14 & Jumlah akar umur $75 \mathrm{hst}$ & $\mathrm{TN}$ \\
15 & Jumlah akar umur $90 \mathrm{hst}$ & $\mathrm{TN}$ \\
16 & Jumlah tunas umur $30 \mathrm{hst}$ & $\mathrm{TN}$ \\
17 & Jumlah tunas umur $45 \mathrm{hst}$ & $\mathrm{TN}$ \\
18 & Jumlah tunas umur $60 \mathrm{hst}$, & $\mathrm{TN}$ \\
19 & Jumlah tunas umur $75 \mathrm{hst}$ & $\mathrm{TN}$ \\
20 & Jumlah tunas umur $90 \mathrm{hst}$ & $\mathrm{TN}$ \\
21 & Berat brangkasan segar & $\mathrm{TN}$ \\
22 & Berat kering oven -1 & $\mathrm{TN}$ \\
\hline
\end{tabular}

Keterangan :

HST : hari setelah tanam

TN : tidak nyata 
Josina: Pengaruh konsentrasi ekstrak bawang merah (allium cepa) terhadap pertumbuhan stek lada (Piper nigrum L.)

Tabel 4.2 Pengaruh pengaruh konsentrasi ekstrak bawang merah (Allium cepa L) tehadap pertumbuhan stek lada (Piper nigrum L).

\begin{tabular}{|c|c|c|c|c|c|c|}
\hline \multirow{2}{*}{ Variabel } & \multirow{2}{*}{ Perlakuan } & \multicolumn{5}{|c|}{ Umur tanaman } \\
\hline & & $30 \mathrm{hst}$ & $45 \mathrm{hst}$ & $60 \mathrm{hst}$ & $75 \mathrm{hst}$ & 90 hst \\
\hline \multirow{5}{*}{ Tanaman } & EO & $3,15 a$ & $3,40 \mathrm{a}$ & $3,90 \mathrm{a}$ & $4,40 \mathrm{a}$ & $4,55 \mathrm{a}$ \\
\hline & $\mathrm{El}$ & $3,83 \mathrm{a}$ & $4,08 \mathrm{a}$ & $4,33 \mathrm{a}$ & $4,58 \mathrm{a}$ & $4,61 \mathrm{a}$ \\
\hline & E2 & $3,72 \mathrm{a}$ & $3,97 \mathrm{a}$ & $4,22 \mathrm{a}$ & $4,47 \mathrm{a}$ & $4,69 \mathrm{a}$ \\
\hline & E3 & $3,64 \mathrm{a}$ & $3,14 \mathrm{a}$ & $4,39 \mathrm{a}$ & $4,89 \mathrm{a}$ & $5,14 \mathrm{a}$ \\
\hline & E4 & $4,25 \mathrm{a}$ & $4,25 \mathrm{a}$ & $4,50 \mathrm{a}$ & $5,00 \mathrm{a}$ & $5,25 \mathrm{a}$ \\
\hline \multicolumn{2}{|c|}{ BNT 5\% } & TN & $\mathrm{TN}$ & $\mathrm{TN}$ & $\mathrm{TN}$ & $\mathrm{TN}$ \\
\hline \multirow{5}{*}{ Panjang akar } & $\mathrm{EO}$ & $3,15 \mathrm{a}$ & $4,15 \mathrm{a}$ & $4,65 \mathrm{a}$ & $5,65 \mathrm{a}$ & $6,65 \mathrm{a}$ \\
\hline & $\mathrm{El}$ & $3,33 \mathrm{a}$ & $4,33 \mathrm{a}$ & $4,83 \mathrm{a}$ & $5,83 \mathrm{a}$ & $6,83 \mathrm{a}$ \\
\hline & $\mathrm{E} 2$ & $3,47 \mathrm{a}$ & $4,47 \mathrm{a}$ & $4,97 \mathrm{a}$ & $5,97 \mathrm{a}$ & $6,97 \mathrm{a}$ \\
\hline & E3 & $3,39 \mathrm{a}$ & $4,39 \mathrm{a}$ & $4,89 \mathrm{a}$ & $5,89 \mathrm{a}$ & $6,64 \mathrm{a}$ \\
\hline & E4 & $3,25 \mathrm{a}$ & $4,25 \mathrm{a}$ & $4,75 \mathrm{a}$ & $5,25 \mathrm{a}$ & $6,25 \mathrm{a}$ \\
\hline \multicolumn{2}{|c|}{ BNT 5\% } & $\mathrm{TN}$ & $\mathrm{TN}$ & $\mathrm{TN}$ & $\mathrm{TN}$ & $\mathrm{TN}$ \\
\hline \multirow{5}{*}{ Jumlah akar } & EO & $2,65 \mathrm{a}$ & $3,65 \mathrm{a}$ & $3,90 \mathrm{a}$ & $4,65 \mathrm{a}$ & $4,90 \mathrm{a}$ \\
\hline & $\mathrm{El}$ & $2,83 \mathrm{a}$ & $3,83 \mathrm{a}$ & $3,08 \mathrm{a}$ & $4,33 \mathrm{a}$ & $4,33 \mathrm{a}$ \\
\hline & E2 & $2,97 \mathrm{a}$ & $3,97 \mathrm{a}$ & $3,72 \mathrm{a}$ & $4,97 \mathrm{a}$ & $4,97 \mathrm{a}$ \\
\hline & E3 & $2,64 \mathrm{a}$ & $3,39 \mathrm{a}$ & $3,39 \mathrm{a}$ & $3,89 \mathrm{a}$ & $4,89 \mathrm{a}$ \\
\hline & E4 & $2,25 \mathrm{a}$ & $3,25 \mathrm{a}$ & $3,75 \mathrm{a}$ & $4,25 \mathrm{a}$ & $4,25 \mathrm{a}$ \\
\hline \multicolumn{2}{|c|}{ BNT 5\% } & $\mathrm{TN}$ & $\mathrm{TN}$ & $\mathrm{TN}$ & $\mathrm{TN}$ & $\mathrm{TN}$ \\
\hline \multirow{6}{*}{ Jumlah tunas } & $\mathrm{EO}$ & $2,80 \mathrm{a}$ & $3,40 \mathrm{a}$ & $4,15 \mathrm{a}$ & $4,15 \mathrm{a}$ & $4,15 \mathrm{a}$ \\
\hline & $\mathrm{El}$ & $3,58 \mathrm{a}$ & $4,08 \mathrm{a}$ & $4,08 \mathrm{a}$ & $4,33 \mathrm{a}$ & $4,58 \mathrm{a}$ \\
\hline & $\mathrm{E} 2$ & $3,72 \mathrm{a}$ & $3,72 \mathrm{a}$ & $4,22 \mathrm{a}$ & $4,47 \mathrm{a}$ & $4,47 \mathrm{a}$ \\
\hline & $\mathrm{E} 2$ & $3,72 \mathrm{a}$ & $3,72 \mathrm{a}$ & $4,22 \mathrm{a}$ & $4,47 \mathrm{a}$ & $4,47 \mathrm{a}$ \\
\hline & E3 & $3,94 \mathrm{a}$ & $4,14 \mathrm{a}$ & $4,14 \mathrm{a}$ & $4,39 \mathrm{a}$ & $4,64 \mathrm{a}$ \\
\hline & $\mathrm{E} 4$ & $3,74 \mathrm{a}$ & $3,75 \mathrm{a}$ & $4,00 \mathrm{a}$ & $4,50 \mathrm{a}$ & $4,00 \mathrm{a}$ \\
\hline \multicolumn{2}{|c|}{ BNT 5\% } & $\mathrm{TN}$ & $\mathrm{TN}$ & $\mathrm{TN}$ & $\mathrm{TN}$ & $\mathrm{TN}$ \\
\hline
\end{tabular}

Keterangan: angka-angka yang diikuti oleh huruf yang sama pada kolom yang sama menunjukan pengaruh yang tidak berbeda nyata pada uji BNT 5\%.

Pemberian konsentarasi ekstrak bawang merah menunjukan pengaruh tidak nyata terhadap semua variabel pertumbuhan stek lada (Tinggi tanaman, Panjang akar, Jumlah akar dan jumlah Tunas. Stek lada pada umur 90 hst menunjukkan tinggi tanaman yang paling tinggi pada perlakuan E4, stek lada pada umur 90 hst menunjukan panjang akar pada perlakuan E2, jumlah akar yang paling banyak pada perlakuan E2, dan jumlah tunas yang paling banyak pada perlakuan E3. 
Josina: Pengaruh konsentrasi ekstrak bawang merah (allium cepa) terhadap pertumbuhan stek lada (Piper nigrum L.)

\section{Berat Segar $\tan ^{-1}$ Berat Kering Oven $\tan ^{-1}$}

Tabel 4.3 Pengaruhpengaruh konsentrasi ekstrak bawang merah (Album cepa L.) tehadap pertumbuhan stek lada (Piper nigrum L.)

\begin{tabular}{ccc}
\hline Perlakuan & Berat segar tan $^{-1}$ & Berat kering oven $\tan ^{-1}$ \\
\hline EO & $11,25 \mathrm{a}$ & $3,50 \mathrm{a}$ \\
E1 & $10,00 \mathrm{a}$ & $3,75 \mathrm{a}$ \\
E2 & $11,25 \mathrm{a}$ & $4,00 \mathrm{a}$ \\
E3 & $11,25 \mathrm{a}$ & $4,00 \mathrm{a}$ \\
E4 & $12,50 \mathrm{a}$ & $4,00 \mathrm{a}$ \\
\hline BNT 5\% & TN & TN \\
\hline Keterangan : & angka-angka yang diikuti oleh huruf yang sama pada kolom yang sama \\
& menunjukan pengaruh yang tidak berbeda nyata pada taraf uji BNT 5\%.
\end{tabular}

Pemberian konsentarasi ekstrak bawang merah yang berbeda berpengaruh tidak nyata terhadap berat segar berangkasan dan berat kering oven tanaman lada. Berat segar $\tan ^{-1}$ yang tertinggi pada perlakuan E4 dan berat kering oven $\tan ^{-1}$ teryinggi pada perlakuan E2, E3, E4.

\section{Pembahasan}

Hasil penelitian menunjukan bahwa pengaruh konsentrasi ekstrak bawang merah (Album cepa L.) tehadap pertumbuhan stek lada (Piper nigrum L.) berpengaruh tidak nyata terhahadap semua perlakuan. Hal ini kemungkinan disebabkan konsentrasi yang diberikan belum cukup dan lama perendaman yang terlalu singkat sehingga kandungan hormon pada ekstrak bawang merah tidak dapat memacu pertumbuhan stek dan tunas tanaman lada. Avery dan Johnson (1947 dalam Rukmana, 2006) menyatakan, bahwa metode perendaman

dilakukan dengan cara merendam stek selama kira-kira 24 jam pada kedalaman 1 inci dalam larutan zat pengatur tumbuh tertentu. Febriani dkk (2012) menyatakan bahwa larutan zat pengatur tumbuh tertentu. Febriani dkk (2012) menyatakan bahwa perendaman selama 2 jam dalam Supernatan Kultur Bacillus sp.2 DUCC-BR-K1 dapat memaju panjang akar.

Dalam hubungannya dengan kemampuan vegetatif tanaman untuk menghasilkan akar dan organ-organ tumbuhan lainnya. Kehadiran tunas pada stek akan membentuk proses pembentuk zat pengatur tumbuh yang kemudian diedarkan ke bagian bawah atau basl untuk membentuk akar, akan tetapi sekalipun suatu stek tidak mempunyai tunas pada ujungnya namun pembentukan akar dapat terjadi dengan pemberian ekstrak bawang merah ataupun senyawa lain yang sejenis dengan itu. 
Josina: Pengaruh konsentrasi ekstrak bawang merah (allium cepa) terhadap pertumbuhan stek lada (Piper nigrum L.)

\section{Kesimpulan}

1. Hasil penelitian menunjukan konsentrasi ekstrak bawang merah (Album cepa L.) berpengaruh tidak nyata tehadap pertumbuhan stek lada (Piper nigrum L).

2. Belum di temukan Konsentrasi yang optimal ekstrak bawang merah untuk memberikan pertumbuhan stek lada yang optimal

\section{UCAPAN TERIMA KASIH}

Pada kesempatan ini penulis ingin mengucapkan terima kasih kepada semua pihak yang telah membantu dengan caranya masing-masing dalam melengkapi tulisan ini.

\section{DAFTAR PUSTAKA}

Anonim. 2009. Pedoman Penanganan Pasca Panen Lada. Direktorat Penanganan Pasca Panen Ditjen Pengolahan dan Pemasaran Hasil Pertanian Departemen Pertanian.

Anonim. 2009. Peranan Zat Pengatur Tumbuh.

http://akmalaakmal.blogspot.com/2009/08/perananzat-pengatur-tumbuh-zpt-dalarn.htm. Diakses 2013 Agustus 25.

Anonim. 2012. Fisiologi Tumbuhan dan Hormon http://makalahcyber.blogspot.com/2012/ 05/materi-fisiologi-tumbuhanhormonpada.htm. Diakses 2013 Agustus 25.

Audus. L. J. 1963. Plant Growth Substances. Interscience Publ. Inc. New York.

Avery, G. S., Johnson E. B. 1947. Hormones and Horticulture. Mc Graw-Hill Book Co. Inc. New York.
Departemen Kehutanan dan Perkebunan. 2003. Budidaya Tanaman Lada Secara Veltkultur. Ditjen Rehabilitasi Lahan dan Perhutanan Sosial. Jakarta.

Dwijoseputro. 1980. Pengantar Fisiologi Tumbuhan. Gramedia. Jakarta.

El Halim, Aulia R.M., dkk. 2009. Pemanfaatan Ekstrak Bawang Merah Sebagai PenggantiRootone-f Untuk Menstimulasi Pertumbuhan Akar Setek Pucuk Jati (Tectona grandis L). Fakultas Kehutanan UGM. Yogyakarta.

Febriani T.P., Sri D., Budi R. 2012. Pengaruh Konsentrasi dan Lama Perendaman dalam Supernatan Kultur Bacillus sp.2 DUCC-BR-K1.3 Terhadap Pertumbuhan Stek Horisontal Batang Jarak Pagar (Jatropha curcas L.) Matematika dan Urnu Pengetahuan Alam Universitas Diponegoro. Semarang.

Gardner F.P., Pearce R.B., Mitchel R.L. 1985. Fisiologi Tanaman Budidaya. Tedemahan. Universitas Indonesia. Jakarta.

Gomez K.C dan Gomez. A. 1995. Prosedur Statistik Untuk Penelitian Pertanian. Edisi Kedua. Universitas Indonesia. Jakarta.

Hulk E.M. 2004. Pengaruh Rootone-F dan Ukuran Diameter Stek Terhadap Pertumbuhan dari Stek Batang Jati (Tectona grandisL.F). Jurusan Kehutanan Fakultas Pertanian Universitas Patimura. Ambon.

Portal Kabupaten Ende. 2012. Potensi Pertanian dan Peternakan Kabupaten Ende.http://portal.endekab.go.id/potensi -daerah/pertanian.html Di unduh tartuyal 01/07/12 Jam 17.24.

Puttileihalat, M. 2001. Pengaruh Rootone-F dan Ukuran Diameter Stek Terhadap Pertumbuhan Tunas Dari Stek Pulai Gading (Alstonia scholaris, R. Br) Jurusan Kehutanan Fakultas Pertanian Universitas Pattimura. Ambon. 
Josina: Pengaruh konsentrasi ekstrak bawang merah (allium cepa) terhadap pertumbuhan stek lada (Piper nigrum L.)

Rukmana, 1994. Budidaya Tanaman Lada. Kanisius, Yogyakarta.

Rochimin dan Hadadi S.S. 1973. Pembiakan Vegetatif. PLP Agronomi. Fakultas Pertanian IPB. Bogor.

Rismunandar. 1987. Lada Budidaya dan Tataniaga. Swadaya. Jakarta.

Rukmana, 2006. Budidaya dan Pertumbuhan Tanaman Lada. Rajawali. Jakarta.

Sutarno dan Andoko A. 2004. Budidaya Lada si Raja Rempah-rempah. Agro Media Pustaka. Jakarta.

Setyowati, Titik. 2004. Pengaruh Ekstrak Bawang Merah (Allium ceps L) dan Ekstrak Bawang Putih (Allium sativum L) Terhadap Pertumbuhan Stek Bunga Mawar (Rosa sinensis L). Skripsi Universitas Muhamadiyah Malang.

Wisnaya, B. 1990. Petunjuk Praktis Bercocok Tanam Lada. Disbun Provinsi Bali. Denpasar. 